\title{
Ventilation of Apartment Buildings and Nursing Homes
}

\author{
Alo Mikola, Teet-Andrus Koiv, Hendrik Voll \\ Department of Environmental Engineering, Tallinn University of Technology, Tallinn, Estonia \\ Email: teet.koiv@ttu.ee, alo.mikola@ttu.ee
}

Received 27 February 2014; revised 27 March 2014; accepted 3 April 2014

Copyright (C) 2014 by authors and Scientific Research Publishing Inc.

This work is licensed under the Creative Commons Attribution International License (CC BY). http://creativecommons.org/licenses/by/4.0/

(c) (i) Open Access

\begin{abstract}
The paper presents the results of the investigations into the indoor climate and energy efficiency of ventilation devices in residential buildings and nursing homes. The indoor climate studies discussed in the article were conducted in a nursing home where room ventilation is based on Meltem Air Handling Units (AHU). Similar studies have been carried out in apartment buildings where $\mathrm{CO}_{2}$ levels in bedrooms were compared before and after renovating the ventilation with Meltem AHU and installing exhaust fans in the bathroom/WC and kitchen. Tenants evaluate the use of Meltem AHU in apartments very positively. The article presents the efficiency results of Meltem AHU with different external air temperatures conducted in apartments in real-life situations. The study shows that skilful renovation of ventilation in old apartment buildings enables to achieve good indoor climate and energy saving at the same time.
\end{abstract}

\section{Keywords}

Indoor Climate, Apartment Buildings, Nursing Home, AHU, Energy Efficiency of AHU

\section{Introduction}

The paper presents the results of the investigations into indoor climate in nursing homes and residential buildings. In the review of ventilation in European dwellings, it was pointed out that the ventilation of residential spaces in Nordic countries is often poor [1]. As a result of refurbishing, the air tightness of the building envelope increases and as many buildings have natural ventilation, the air change rate is reduced. The performances of the ventilation systems in low-energy residential houses have been presented by Maier et al. [2]. The energy performance of heat recovery units has been investigated by Jaber et al. [3] and Laverge et al. [4]. Ventilation heat recovery in residential buildings has been investigated by Dodoo et al. [5]. A number of studies on the ventilation and indoor air quality in apartment buildings have been carried out at Tallinn University of Technology by Mikola and Koiv [6]-[9]. 


\section{Methodology}

\subsection{Indoor Air Quality}

In accordance with the requirements [10] in Estonia, the living area must have natural or mechanical ventilation, which guarantees the air change necessary for human activity. According to the requirements in Estonia [11], air velocity in living spaces, the volume of space per person and the content of harmful substances in the indoor air must not exceed the permitted values.

Values for assessing room temperatures are taken from Estonian standard EVS-EN 15251:2007 [10]. This standard describes indoor environmental input parameters for designing and assessing the energy performance of buildings. The temperature values in case of different classes of thermal comfort are described in Table 1. The values to assess the relative humidity of indoor air are taken from Estonian indoor climate standard EVS 839:2003 [12]. The parameters are described in Table 1.

On the valid regulative basis, the $\mathrm{CO}_{2}$ concentration in the indoor air in Estonia is set in the standard of indoor environmental input parameters [10] and designing criteria CR 752 [13]. Danish University of Technology has studied the standard in detail and gives the air flow rate of the classes of indoor climate and the maximum norms of the $\mathrm{CO}_{2}$ content in the indoor air [14]. These norms also correspond to the values that are given in the designing criteria of indoor climate. Due to that the present study uses the maximum values given in designing criteria CR 752 for accessing the $\mathrm{CO}_{2}$ content in the indoor air, whereby the $\mathrm{CO}_{2}$ content in the external air is considered to be $350 \mathrm{ppm}$. The values to assess the $\mathrm{CO}_{2}$ concentration of indoor air are described in Table 2 . The standard for determining the initial parameters of energy efficiency [10] allows short-time deviations from the required parameters of indoor climate. The permitted deviation is up to $5 \%$.

According to the standard for determining the initial parameters of energy efficiency (EVS-EN 15251:2007), it is possible to deduce the airflow according to the measurements of $\mathrm{CO}_{2}$ concentrations in rooms where the main source of indoor air pollution is people. This method is called the metabolic $\mathrm{CO}_{2}$ method. To assess the air change of a room by the metabolic $\mathrm{CO}_{2}$ method it is possible to use Equation (1):

$$
C=C_{v}+\frac{m}{L}-\left(C_{v}+\frac{m}{L}-C_{0}\right) \cdot\left(\mathrm{e}^{-\frac{L}{V} \tau}\right)
$$

where $C$ is the indoor concentration of $\mathrm{CO}_{2}$ at time $t\left(\mathrm{~g} / \mathrm{m}^{3}\right), C_{v}$ the concentration of $\mathrm{CO}_{2}$ in the external air $\left(\mathrm{g} / \mathrm{m}^{3}\right), C_{0}$ the concentration of $\mathrm{CO}_{2}$ in the indoor air at time $0\left(\mathrm{~g} / \mathrm{m}^{3}\right), \mathrm{L}$ the volume flow rate of air entering the space $\left(\mathrm{m}^{3} / \mathrm{h}\right)$, $\mathrm{m}$ the volumetric indoor emission rate of $\mathrm{CO}_{2}(\mathrm{~g} / \mathrm{h}), V$ the volume of the indoor space $\left(\mathrm{m}^{3}\right)$ and $\tau$ is the interval since $t=0$.

Using literature [15], it is possible to express the relationship between the metabolic heat rate, body surface area and oxygen demand by Equation (2).

Table 1. Thermal classes of indoor climate based on Estonian standards EVS-EN 15251:2007 and EVS 839:2003.

\begin{tabular}{ccccc}
\hline \multirow{2}{*}{$\begin{array}{c}\text { Class of } \\
\text { thermal comfort }\end{array}$} & \multicolumn{2}{c}{ Summer } & \multicolumn{2}{c}{ Winter } \\
\cline { 2 - 4 } & Relative humidity, \% & Room temperature, ${ }^{\circ} \mathrm{C}$ & Relative humidity, \% & Room temperature, ${ }^{\circ} \mathrm{C}$ \\
\hline I & & $23.5-25.5$ & $21-25$ \\
II & $30-70$ & $23.0-26.0$ & $25-45$ & $20-25$ \\
III & $22.0-27.0$ & $18-25$ \\
\hline
\end{tabular}

Table 2. Class of the indoor climate for rooms with human activity (CR 1752) [13].

\begin{tabular}{cccc}
\hline Category & Expected percentage dissatisfied, \% & $\begin{array}{c}\mathrm{CO}_{2} \text { concentration at outdoor } \\
\text { air level } 350 \mathrm{ppm} \text {, ppm }\end{array}$ & Indoor air $\mathrm{CO}_{2}$ concentration, ppm \\
\hline I (A) & 15 & 460 & 810 \\
II (B) & 20 & 660 & 1010 \\
III (C) & 30 & 1190 & 1540 \\
\hline
\end{tabular}




$$
Q_{\mathrm{CO}_{2}}=\frac{0.727 \cdot M \cdot R Q \cdot m^{0.425} \cdot l^{0.725}}{4.83 \cdot R Q+16.17}
$$

where $Q_{\mathrm{CO}_{2}}$ is the human indoor emission rate of $\mathrm{CO}_{2}(\mathrm{l} / \mathrm{h}), R Q$ the ratio of $\mathrm{M} \mathrm{O}_{2}$ and exhaled $\mathrm{CO}_{2}, Q_{\mathrm{O}_{2}}$ human oxygen demand $(\mathrm{l} / \mathrm{h}), \mathrm{m}$ the weight of person $(\mathrm{kg}), \mathrm{l}$ the height of person $(\mathrm{m}), \mathrm{M}$ the metabolic heat rate $\left(\mathrm{W} / \mathrm{m}^{2}\right)$.

Human $\mathrm{CO}_{2}$ emission rates are mainly related to the surface area of the body and the metabolic heat rate. The ratio of inhaled $\mathrm{O}_{2}$ and exhaled $\mathrm{CO}_{2}$ is taken as a constant value in the present study (0.7 to 1.2 met). If the value of RG is not exactly determined, it can be considered 0.83 [15]. In this case the accuracy of $\mathrm{CO}_{2}$ emissions is approximately $3 \%$, which is a sufficient result.

The metabolic $\mathrm{CO}_{2}$ emissions are often observed as the average value of a $24 \mathrm{~h}$ period. In this case the average metabolic $\mathrm{CO}_{2}$ emission is calculated using the weighted average method. In some studies the metabolic $\mathrm{CO}_{2}$ emissions are shown during the sleeping period. As the $\mathrm{CO}_{2}$ emissions vary in a wide range in the day time, it would often be much more punctual to use the night time $\mathrm{CO}_{2}$ emissions in the calculations [10]. In the present study night time $\mathrm{CO}_{2}$ emissions are used in the case of apartment buildings. In this study adult $\mathrm{CO}_{2}$ emission is $13 \mathrm{l} / \mathrm{h}$ and children's $\mathrm{CO}_{2}$ emission is $6.5 \mathrm{l} / \mathrm{h}$ during the night time. Metabolic $\mathrm{CO}_{2}$ emissions in different studies are shown in Table 3.

\subsection{Ventilation Heat Recovery}

Member States of the European Union are required to implement energy efficiency measures for buildings under the Energy Performance of Building Directive [16]. With new building codes, EU member states intend to reduce the total energy consumption in buildings by making the buildings well-insulated and tighter. Due to the tighter and well-insulated constructions, the ventilation loads constitute a growing part of the heating demand between 30\% - 60\% for new and retrofitted buildings [17]. As the ventilation heating demand plays an important role in the building's total heating demand, the heat exhaust air heat recovery is inevitable.

From the exhaust air it is possible to recover only sensible heat or both sensible and latent heat [18] [19]. Energy is used to cover the heat losses due to ventilation air and to move the ventilation air for mechanical ventilation. The ventilation system also influences the air infiltration through the building envelope.

The temperature efficiency, which does not include latent heat transfer, was used to quantify the effect of heat recovery. The temperature ratio (efficiency) $\eta_{\text {temp }}$ is defined as [18] [20]:

$$
\eta_{\text {temp }}=\frac{\dot{m}_{\text {in }} \cdot\left(\overline{t_{\text {supply }}}-t_{\text {outdoor }}\right)}{\dot{m}_{\text {min }} \cdot\left(t_{\text {exhausst }}-t_{\text {outdoor }}\right)}
$$

$t_{\text {outdoor }}$ is the outside air temperature, $t_{\text {exhaust }}$ is the temperature of the extract air, $\dot{m}_{\text {in }}$ is the inlet mass flow rateand $\dot{m}_{\min }$ is the minimum of inlet and outlet mass flows. In the case of the regenerator, a time-averaged value of the supply air temperature $\overline{t_{\text {supply }}}$ has to be used which is given by [20]:

$$
t_{\text {supply }}=\frac{1}{\tau} \int_{t=0}^{t=\tau} t_{\text {supply }}(t) \cdot \mathrm{d} t
$$

Table 3. Metabolic $\mathrm{CO}_{2}$ emissions in different studies [21]-[26].

\begin{tabular}{cccc}
\hline Country, study & Object of the study & Adult $\mathrm{CO}_{2}$ emission, $\mathrm{l} / \mathrm{h}$ & Infant $\mathrm{CO}_{2}$ emission, $\mathrm{l} / \mathrm{h}$ \\
\hline USA, Dietz \& Goodrich 1995 & Schools, residential buildings & 19 & 12 \\
Thailand, Leephakpreeda et al. 2000 & Schools & 16.2 & 16.2 \\
Ireland, Guo and ja Lewis 2007 & Residential buildings & 18 & 18 \\
Sweden, Pavlovas 2003 & Apartment buildings & $12^{*}$ & $12^{*}$ \\
Czech, Jokl 2000 & $\begin{array}{c}\text { Schools, office buildings, } \\
\text { residential buildings }\end{array}$ & $19(1-1.2$ met) & 18 (3 - 6 yrs and 2.7 met); \\
Estonia, Kalamees et al. 2012 & Apartment buildings & $13^{*}-1.2$ met) & $6.5^{*}$ (until 14 yrs) \\
\hline
\end{tabular}

*-night-time. 
$t$ denotes the time and $\tau$ is the semi-period, which means the duration of a supply or extract process. In the case of the recuperator, the process is in a steady state [20]:

$$
t_{\text {supply }}(t)=\text { constant }
$$

\subsection{Studied Buildings}

Studies have been carried out for the nursing home at Alutaguse, Figure 1. This nursing home has 39 rooms for $1-2$ persons, the ventilation of which is solved with Meltem AHU.

The nursing home has hotel type rooms, the area is $25 \mathrm{~m}^{2}$. The rooms are designed for 2 people (Figures 2-4) but in reality 1 or 2 people live in a room. Meltem Komfort AHU with network control has been installed in the rooms. Figure 3 also shows that with the Meltem AHU polluted air is extracted from the bathroom and the supply air is given to the living room.

Meltem AHU can be installed in the wall construction, Figure 5 or on the wall.

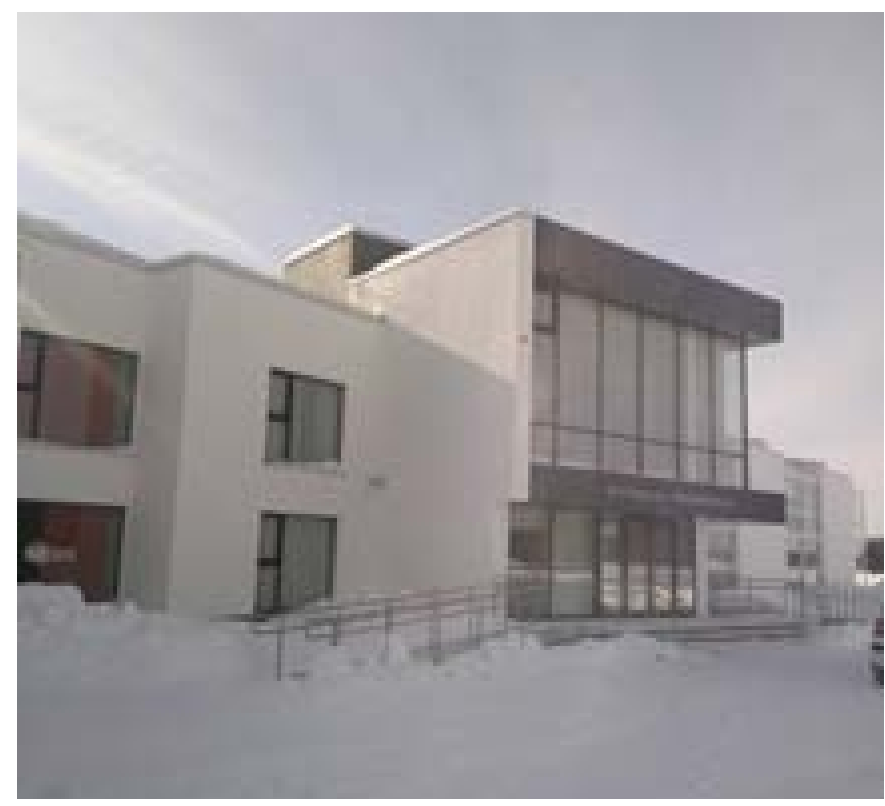

Figure 1. Outside view of the nursing home.

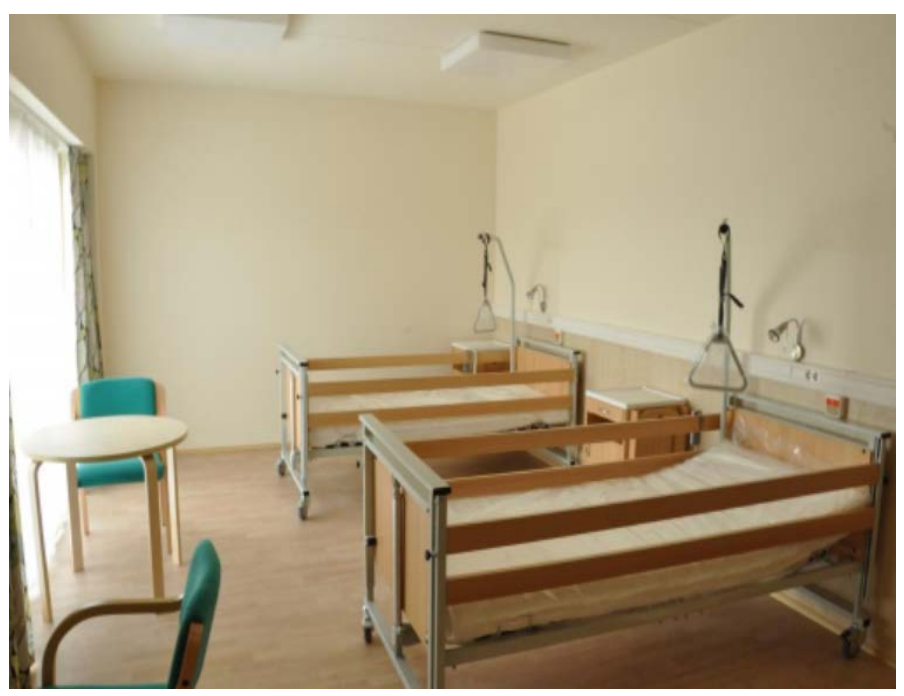

Figure 2. A two-person room. 


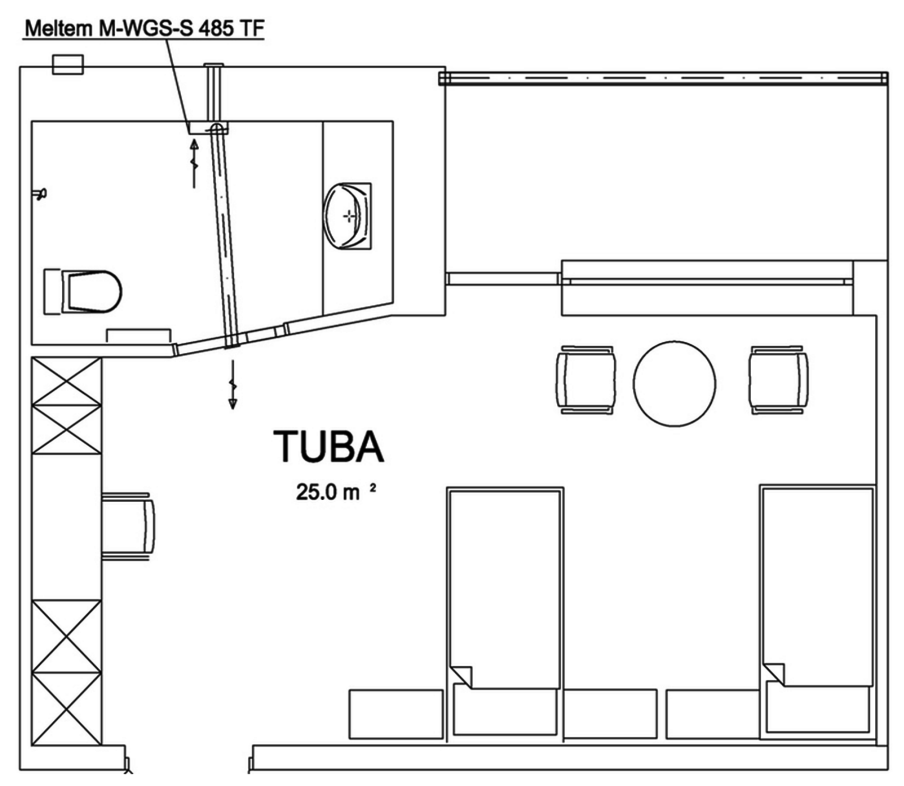

Figure 3. 2-person room solution with Meltem AHU.

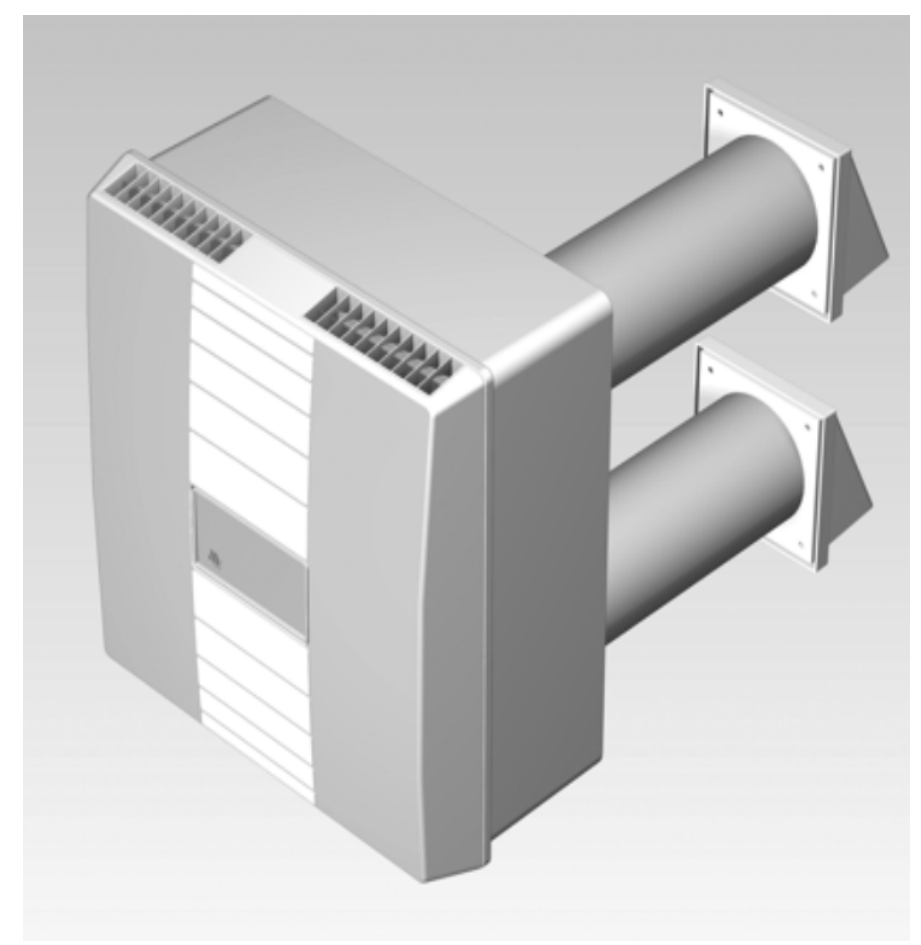

Figure 4. Meltem AHU is installed at the height of $2 \mathrm{~m}$.

Meltem device has an aluminium recuperative heat exchanger, two ventilators, two filter cassettes and a control device.

Meltem room AHU has the same working principles as a standard air handling unit.

A specific feature is that the device serves up to 2 rooms, so the necessary length of the duct is minimal, typically up to $2 \mathrm{~m}$, and the service is located in the AHU room. Thanks to short ducts and EC motors the electrical power of the devices is up to $15 \mathrm{~W}$ maximum, and hence the electric energy consumption is about $120 \mathrm{kWh}$ per year, which is significantly lower than with the central balancing system.

The height of the device is $409 \mathrm{~mm}$, the width is $388 \mathrm{~mm}$ and the depth is $196 \mathrm{~mm}$. It is possible to use: stan- 


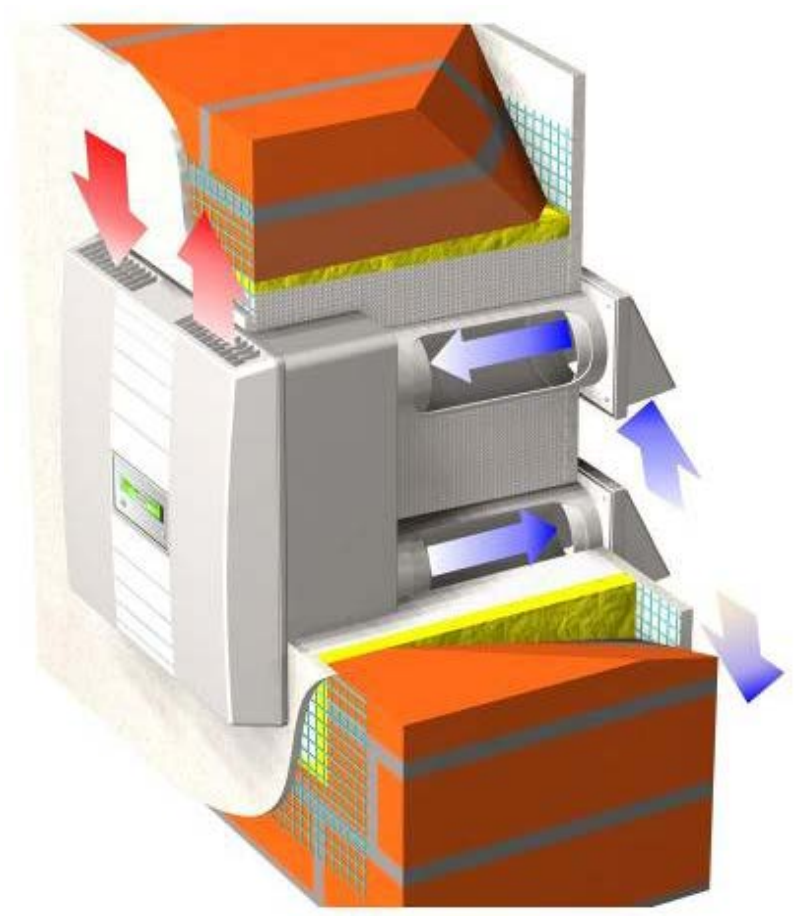

Figure 5. The operation principle of the unit Meltem.

dard filter G4, allergy F7 or absorbent carbon filter F6.

Meltem AHU is available in three modifications: Standart, Standart with network control and Komfort.

According to technical documentation Standart AHU enables three flow rates: 15/30/60 $\mathrm{m}^{3} / \mathrm{h}$, power consumption from 3.8 to $12.5 \mathrm{~W}$ and noise level from 15.5 to $36 \mathrm{~dB}(\mathrm{~A})$.

Research of Meltem AHU in apartment buildings (Figure 6) was mostly carried out in a 2-room apartment, Figure 7 and in 3-room apartments. The apartments were fitted with Komfort devices.

As the HVAC requirements of a nursing home and residential building are close, we can also apply the studies of Meltem AHU conducted in apartments to a nursing home.

Figure 6 shows that one Meltem AHU is used in a 2-room apartment. In addition to AHU, an exhaust ventilator has been installed in the toilet/bathroom, which works when the lighting is switched on, and in the kitchen when required. The fans have been programmed to run up to 10 minutes after the light is turned off. After that the ventilation works as natural. The exhaust air ventilator is shown in Figure 8.

As the ventilator capacity is $64 \mathrm{~m}^{3} / \mathrm{h}$, this ensures good indoor climate in the room while being used. If the ventilator is not in use, the necessary air change is ensured by natural ventilation.

\section{Results}

\subsection{Measurements of Indoor Climate}

\subsubsection{The Nursing Home}

Indoor climate studies in the nursing home were carried out in 4 rooms, 2 of them were single rooms and 2 double rooms. The recording results of $\mathrm{CO}_{2}$ concentration and relative humidity in different rooms of the nursing home are presented in Figures 9-11.

Figure 9 shows that the relative humidity does not exceed the permissible limits of residential premises.

Economic calculations indicate that the construction costs of the ventilation on the bases of Meltem AHU and a centralised system in the nursing home are almost equal. At the same time the power consumption is lower and Meltem device allows flexible use, so the maintenance costs are significantly lower. Due to the lack of metallic ducts the number of light negative ions in the room air is also higher.

The results of the measurements conducted in different rooms show us that room air handling unit Meltem with heat recovery ensures good indoor climate in the nursing home. At the same time rational organization of 


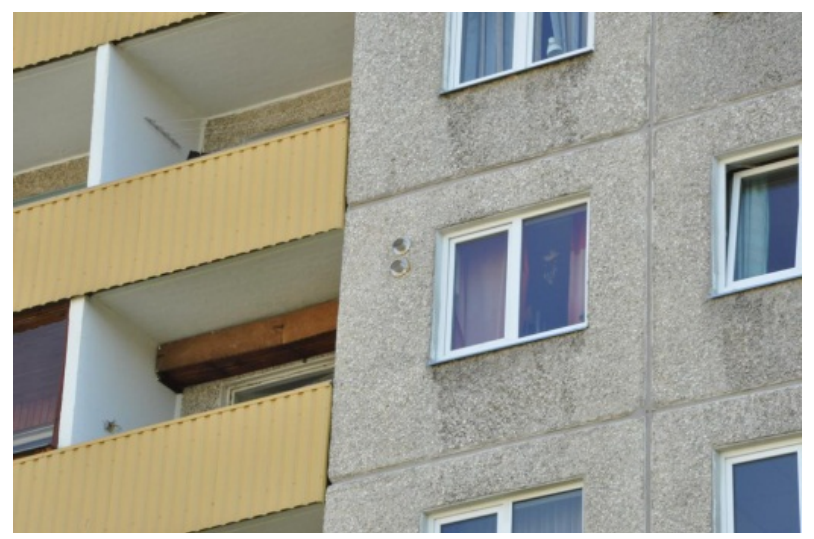

Figure 6. Facade of the house.

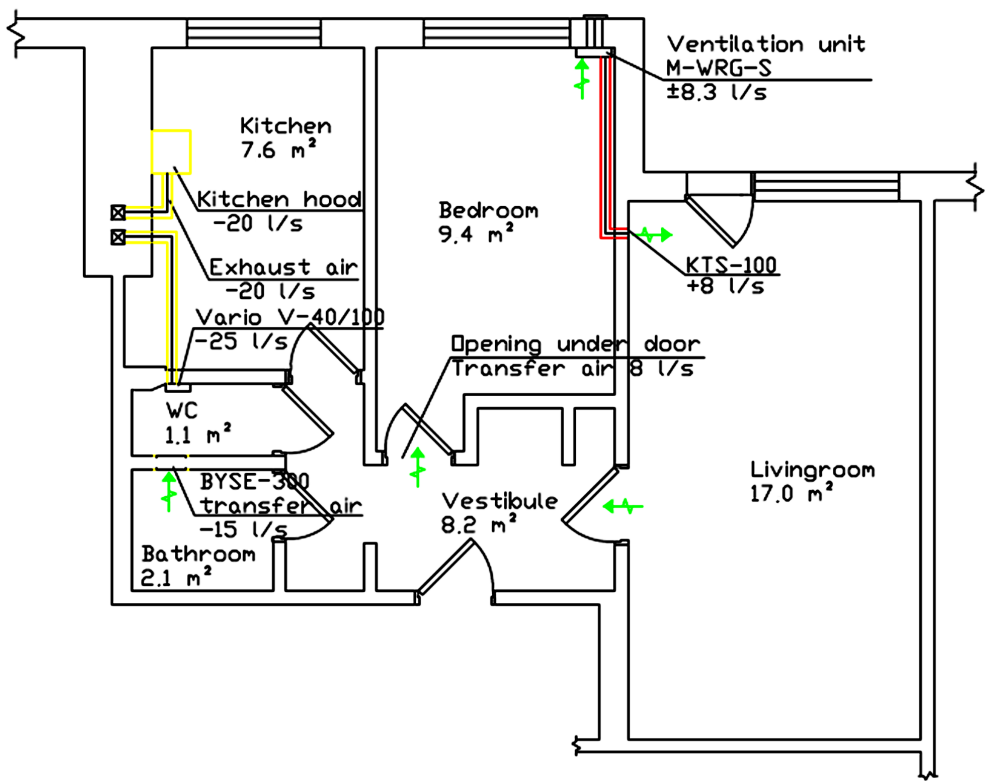

Figure 7. Meltem AHU in a 2-room apartment.

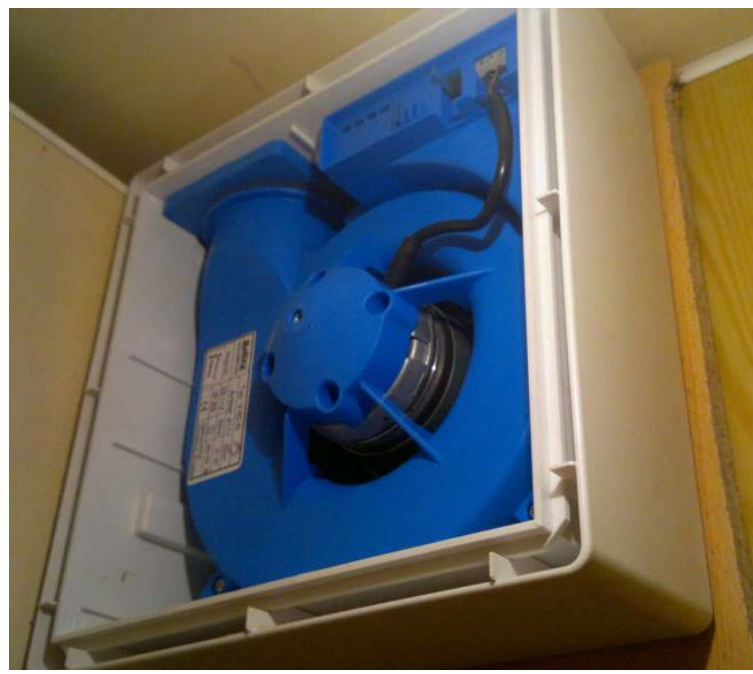

Figure 8. Ventilator in the WC/bathroom, Vario V-40/60. 


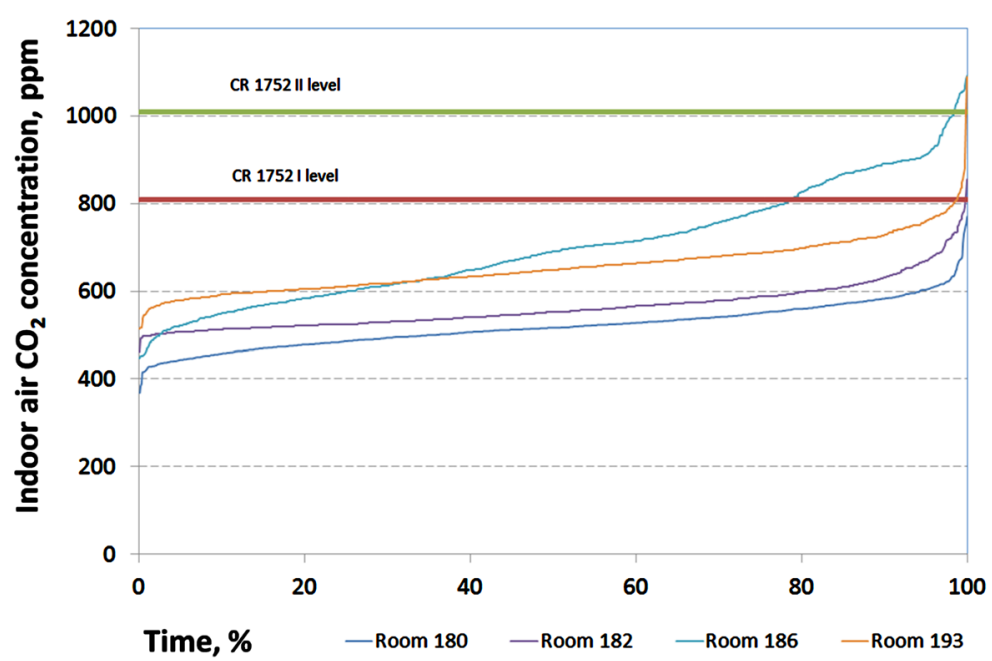

Figure 9. Cumulative distribution of $\mathrm{CO}_{2}$ concentration in different rooms of the nursing home.

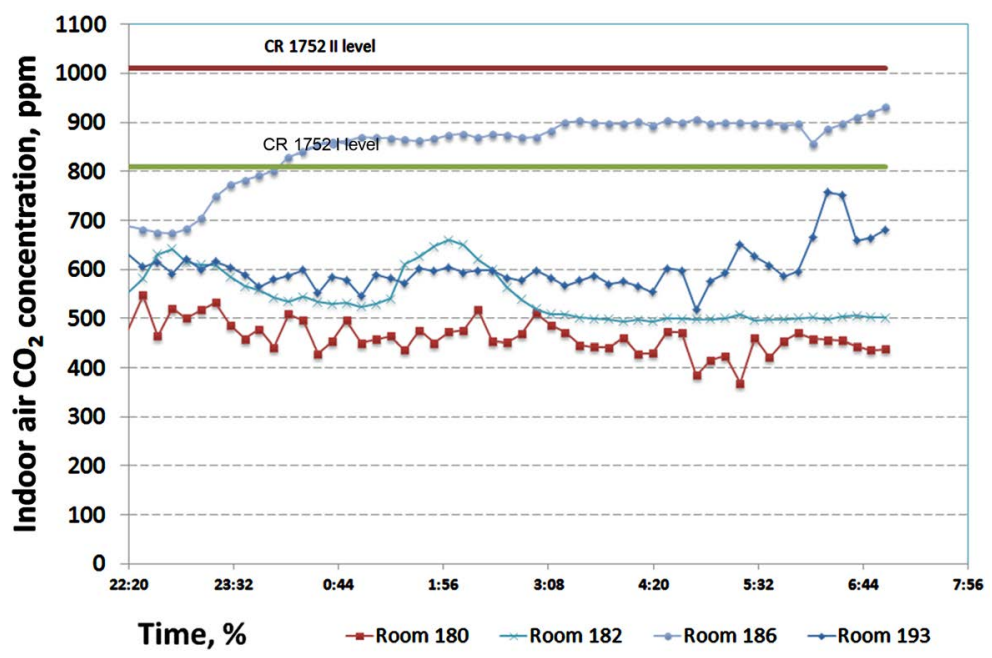

Figure 10. $\mathrm{CO}_{2}$ concentration in different rooms, air flow rate $25 \mathrm{~m}^{3} / \mathrm{h}$.

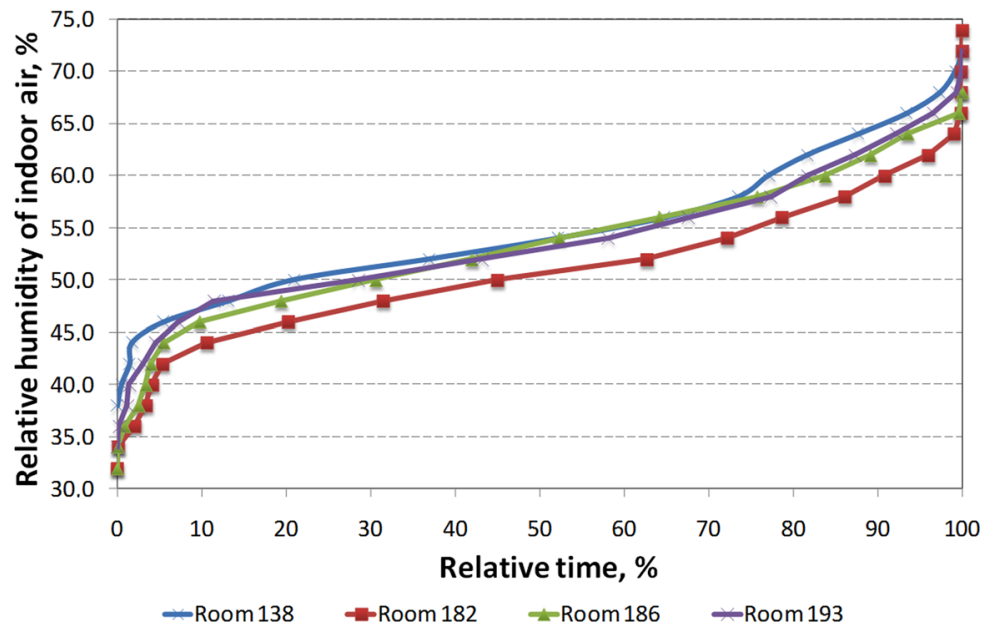

Figure 11. Relative humidity graphs in 4 rooms of the nursing home. 
ventilation by Meltem significantly contributes to energy saving compared with balance ventilation.

We see that the carbon dioxide concentration in rooms was less than $1000 \mathrm{ppm}$, which can be considered a good result, and in the majority of the rooms less than $700 \mathrm{ppm}$, which can be considered a very good result.

\subsubsection{Apartment Buildings}

In apartment buildings studies of $\mathrm{CO}_{2}$ concentration, relative humidity and temperature were carried out after renovating the ventilation. $\mathrm{CO}_{2}$ level after the installation of Meltem AHU is shown in Figure 12 and Figure 13.

In Figure 12 we see that the concentration of $\mathrm{CO}_{2}$ in the bedroom after ventilation renovation was less than $1200 \mathrm{ppm}$, with $70 \%$ of the time less than $1000 \mathrm{ppm}$, which can be considered a good result. The living room had somewhat higher $\mathrm{CO}_{2}$ levels but more than $90 \%$ of the time the concentration was below $1500 \mathrm{ppm}$.

Tenants' assessment of the use of Meltem AHU in apartments has been very positive. Carbon dioxide levels in the bedroom have dropped nearly $1000 \mathrm{ppm}$.

An important study in the meaning of energy consumption was the determination of the temperature ratio of Meltem AHU. The measurement results are shown in Figures 14-16.

The temperature ratios for Meltem AHU with a wide range of external temperature are shown in Figure 14.

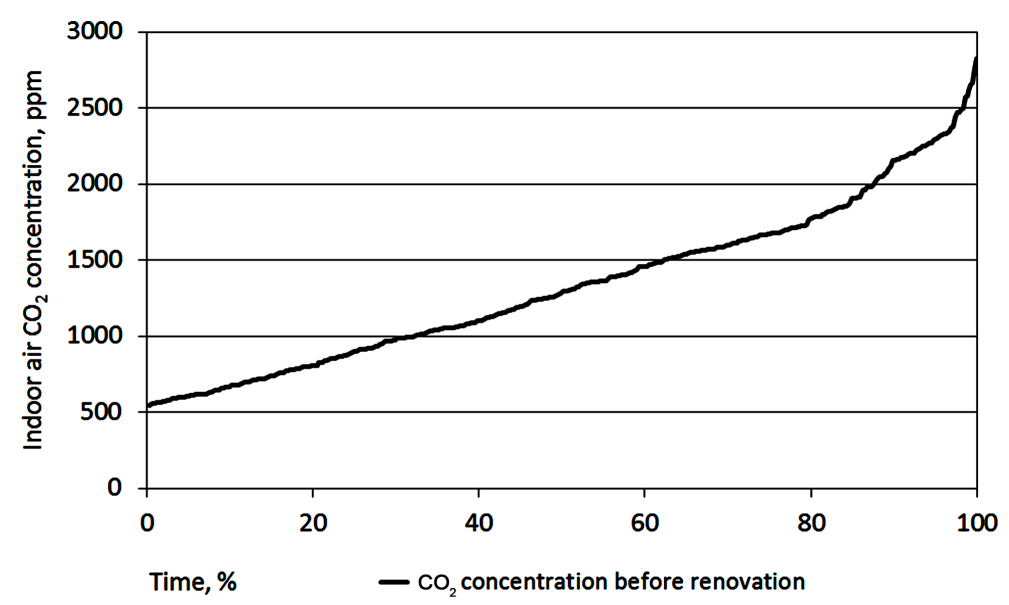

Figure 12. $\mathrm{CO}_{2}$ concentration in the indoor air before renovating the ventilation (apartement building).

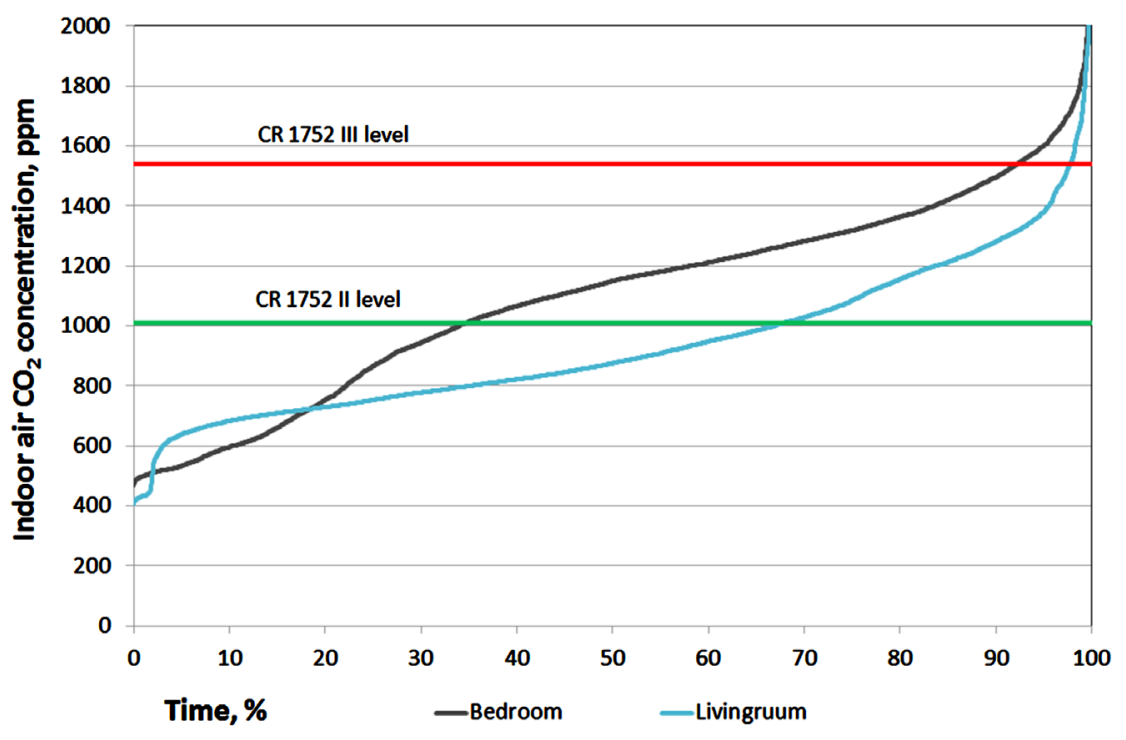

Figure13. $\mathrm{CO}_{2}$ concentration after the installation of Meltem AHU. 


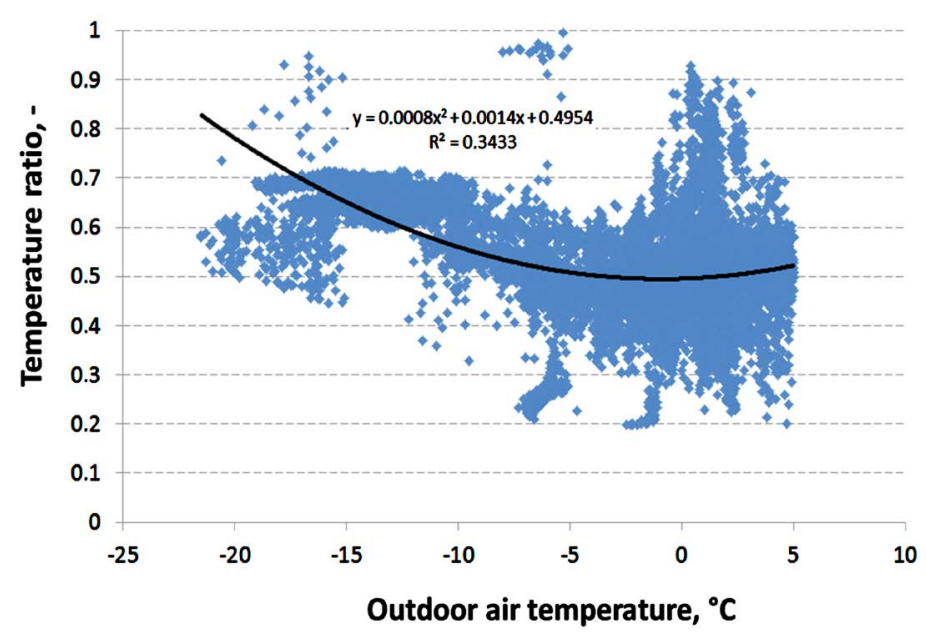

Figure 14. Temperature ratios for Meltem AHU with a wide range of external temperature.

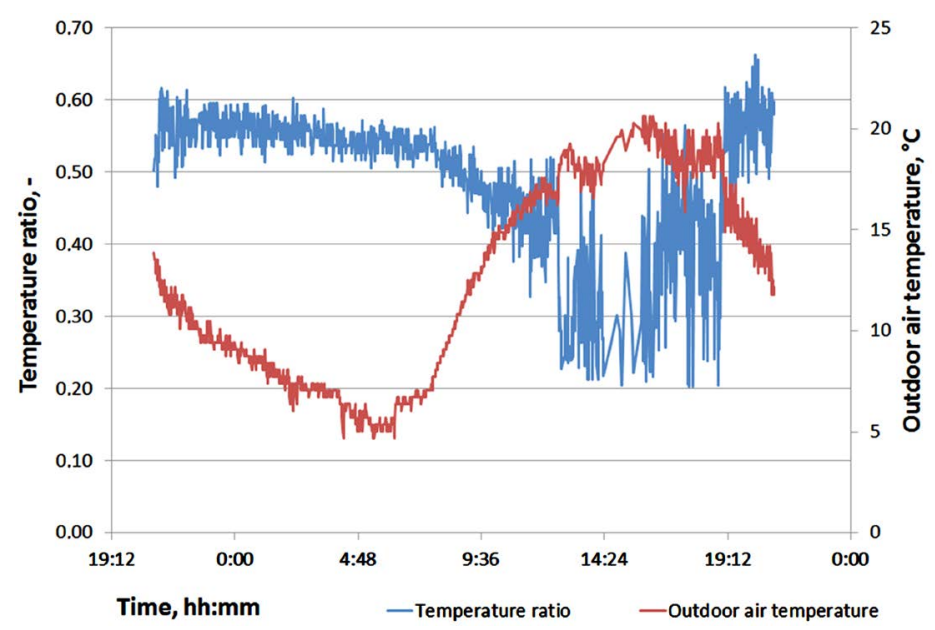

Figure 15. Temperature ratios and outdoor air temperatures for Meltem AHU at the 5th speed.

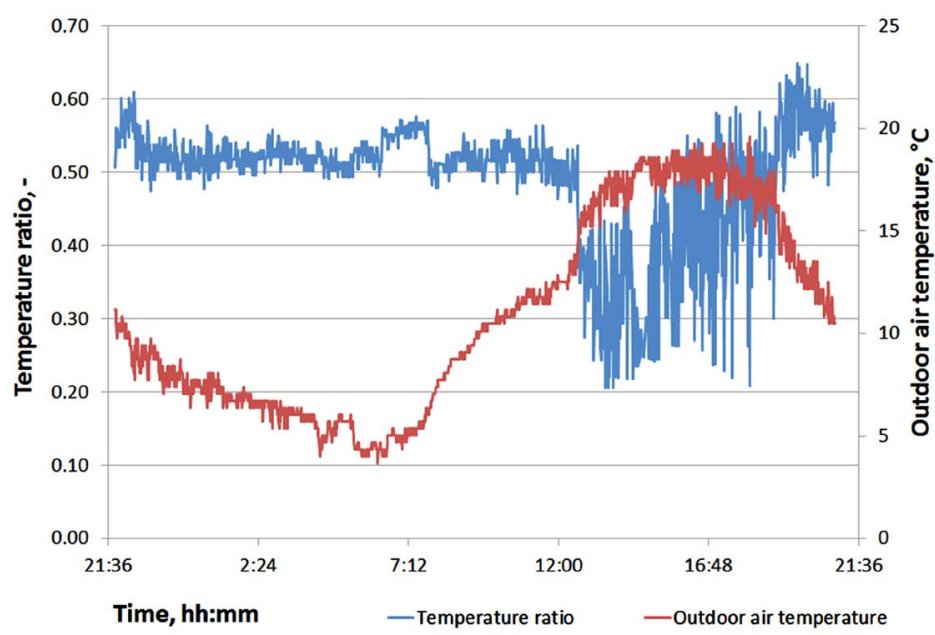

Figure 16. Temperature ratios and outdoor air temperatures for Meltem AHU at the 3rd speed. 
Table 4. Noise levels of Meltem AHU-the average of 30 s (Komfort device).

\begin{tabular}{ccccc}
\hline Speed & $\begin{array}{c}\text { Air flow rate } \\
\mathrm{m}^{3} / \mathrm{h}\end{array}$ & $\begin{array}{c}\text { Noise level in the centre } \\
\text { of living room } \mathrm{dB}(\mathrm{A})\end{array}$ & $\begin{array}{c}\text { Noise level in the centre } \\
\text { of children room dB (A) }\end{array}$ & $\begin{array}{c}\text { Noise level in the centre } \\
\text { of bedroom dB (A) }\end{array}$ \\
\hline Backround noise & 0 & 22 & 24.6 & 23.7 \\
1 & 15 & 22.9 & 25.2 & 26 \\
2 & 30 & 24.1 & 25.8 & 34.8 \\
\hline
\end{tabular}

In testing Meltem AHU in the range of outdoor air temperature from $+5^{\circ} \mathrm{C}$ to $-20^{\circ} \mathrm{C}$, the average temperature ratio (efficiency) was between $40 \%$ to $65 \%$, with a medium size of $60 \%$. In Figure 15 and Figure 16 we can see temperature ratios of Meltem AHU with the 3rd and 5th speed in positive outdoor temperatures. We can see that both temperature ratios are close, with minimum superiority to the fifth speed.

We can see that in real operating conditions the temperature ratio of Meltem AHU is on average close to 0.6, which can be considered a good result.

It should be noted that in old apartment buildings with natural ventilation the use of Meltem AHU in renovating the ventilation is one of the few suitable solutions.

\subsection{Control of the Noise Level}

Test measurements of the noise level of Meltem AHU have been carried out in 2-room apartments. The measurements were carried out at 5 flow rates next to the device, specifically $0.3 \mathrm{~m}$ from the device. Meltem AHU devices were installed in the premises of $10 \mathrm{~m}^{2}$, where people sleep.

According to existing normative documents, the noise level should not exceed $30 \mathrm{~dB}(\mathrm{~A})$ in the bedroom at night and $40 \mathrm{~dB}(\mathrm{~A})$ in the living room during the day. For measuring the device Delta OHM HD 2010 was used.

The measurement results can be evaluated on the basis of the data given in Table 4. It is seen that Komfort AHU can be used at night at the air flow rate of $15 \mathrm{~m}^{3} / \mathrm{h}$, and with certain reservations at the air flow rate of 30 $\mathrm{m}^{3} / \mathrm{h}$. If someone sleeps in the next room, the device can be used at the air flow rate of $30 \mathrm{~m}^{3} / \mathrm{h}$.

\section{Conclusions}

The study shows that the new ventilation solution based on Meltem AHU is perfectly suitable for ventilating rooms in nursing homes and apartments. In the nursing home, Meltem AHU could provide good indoor air conditions in the rooms where two persons live and very good results in the rooms with one person. Measuring results conducted in different rooms show that the room air handling unit with heat recovery ensures good indoor climate in the nursing home. In apartment buildings, people's assessment of the use of Meltem AHU in apartments was very positive. The same studies showed that the temperature ratio of AHU was on average $60 \%$ over the season and the quality of indoor environment was satisfactory. Investigation proved that with rational and reasonable organization of ventilation we can save energy in renovating the ventilation in old apartment buildings.

Investments on ventilation with room air handling unit Meltem are close to those with the central balanced ventilation system, for example, in the nursing home.

The running costs of ventilation with the room air handling unit are lower than that with the central balanced ventilation system. The study shows that skilful renovation of ventilation in old apartment buildings enables to get satisfactory indoor climate and energy saving at the same time.

\section{Acknowledgements}

The research was supported by the Estonian Research Council, with Institutional research funding grant IUT1-15 and with the project "Development of efficient technologies for the air change and ventilation necessary for the increase in the energy efficiency of buildings, AR12045", financed by SA Archimedes. The publication of this article was supported by the ESF measure 1.2.4 Development of cooperation and innovation in universities, the sub-measure "Doctoral Schools" that finances the project "Construction and Environmental Engineering PhD School”-project code 1.2.0401.09-0080. 


\section{References}

[1] Frontczak, M. and Wargocki, P. (2011) Literature Survey on How Different Factors Influence Human Comfort in Indoor Environments. Building and Environment, 46, 922-937. http://dx.doi.org/10.1016/j.buildenv.2010.10.021

[2] Maier, T., Krzaczek, M. and Tejchman, J. (2009) Comparison of Physical Performances of the Ventilation Systems in Low-Energy Residential Houses. Energy and Buildings, 41, 337-353. http://dx.doi.org/10.1016/j.enbuild.2008.10.007

[3] Jaber, S. and Ajib, S. (2012) Energy Recovery System in Mediterranean Region. Sustainable Cities and Society, 3, 166. http://dx.doi.org/10.1016/j.scs.2012.01.002

[4] Laverge, J. and Janssens, A. (2012) Heat Recovery Ventilation Operation Traded off against Natural and Simple Exhaust Ventilation in Europe by Primary Energy Factor, Carbon Dioxide Emission, Household Consumer Price and Exergy. Energy and Buildings, 50, 315-323. http://dx.doi.org/10.1016/j.enbuild.2012.04.005

[5] Dodoo, A., Gustavsson, L. and Sathre, R. (2000) Primary Energy Implications of Ventilation Heat Recovery in Residential Buildings. Energy and Buildings, 31, 37-47.

[6] Koiv, T.-A., Mikola, A. and Kuusk, K. (2012) Energy Efficiency and Indoor Climate of Apartment Buildings in Estonia. International Journal of Energy Science, 2, 94-99.

[7] Koiv, T.-A., Voll, H., Mikola, A., Kuusk, K. and Maivel, M. (2010) Indoor Climate and Energy Consumption in Residential Buildings in Estonian Climatic Condition. Wseas Transactions on Environment and Development, 6, 247-256.

[8] Mikola, A. and Koiv, T.-A. (2011) Indoor Air Quality in Apartment Buildings of Estonia. Computers and Simulation in Modern Science: Selected Papers from WSEAS Conferences, V, 257-261.

[9] Koiv, T.-A. (2007) Indoor Climate and Ventilation in Tallinn School Buildings. Proceedings of the Estonian Academy of Sciences: Engineering, 13, 17-25.

[10] EVS-EN 15251:2007 (2010) Indoor Environmental Input Parameters for Design and Assessment of Energy Performance of Buildings Addressing Indoor Air Quality, Thermal Environment, Lighting and Acoustics. Estonian Centre for Standardisation.

[11] Regulation of the Government of Estonia No. 38. Dwelling Requirements. 26.01.1999 (RT I 1999, 9, 38) In Estonian.

[12] EVS 839:2003 (2003) Indoor Climate. Estonian Center of Standards (In Estonian).

[13] CR 1752 (1998) Ventilation for Buildings: Design Criteria for the Indoor Environment. European Committee for Standardization, Brussels.

[14] Olesen, B.W. (2007) The Philosophy behind EN15251: Indoor Environmental Criteria for Design and Calculation of Energy Performance of Buildings. Energy and Buildings, 39, 740-749. http://dx.doi.org/10.1016/j.enbuild.2007.02.011

[15] ASHRAE (1993) Handbook of Fundamentals. American Society of Refrigerating and Air Conditioning Engineers, Inc., Atlanta.

[16] European Commission (2007) 2020 Vision: Saving Our Energy. Office for Official Publications of the European Communities. http://books.google.ee/books/about/2020_vision.html?id=ujsoAQAAMAAJ\&redir_esc=y

[17] Gustavsson, L., Dodoo, A. and Sathre, R. (2011) Impact of Ventilation Heat Recovery on Primary Energy Use of Apartment Buildings Built to Conventional and Passive House Standard. World Renewable Energy Congress, Linköping, May 2011, 8-11.

[18] Diemanu, J., Roth, K.W. and Brodrick, J. (2003) Air-to-Air Energy Recovery Heat Exchangers. ASHRAE Journal, 45, 57-58.

[19] Fouih, Y.E., Stabat, P., Riviere, P., Hoang, P. and Archambault, V. (2012) Adequacy of Air-to-Air Heat Recovery Ventilation System Applied in Low Energy Buildings. Energy and Buildings, 54, 29-39. http://dx.doi.org/10.1016/j.enbuild.2012.08.008

[20] Manz, H., Huber, H., Schälin, A., Weber, A., Ferrazzini, M. and Studer, M. (2000) Performance of Single Room Ventilation Units with Recuperative or Regenerative Heat Recovery. Energy and Buildings, 31, 37-47. http://dx.doi.org/10.1016/S0378-7788(98)00077-2

[21] Dietz, R.N. and Goodrich, R.W. (1995) Measurement of HVAC System Performance and Local Ventilation Using Passive Perfluorocarbon Tracer Technology. Informal Report, BNL-61990, State University of New York, Farmingdale.

[22] Guo, L. and Lewis, O.J. (2007) Carbon Dioxide Concentration and Its Application on Estimating the Air Change Rate in Typical Irish Houses. The International Journal of Ventilation, 6, 235-245.

[23] Leephakpreeda, T., Thitipatanapong, R., Grittiyachot, T. and Yungchareon, V. (2001) Occupancy-Based Control of Indoor Air Ventilation: A Theoretical and Experimental Study. ScienceAsia, 27, 279-284. 
http://dx.doi.org/10.2306/scienceasia1513-1874.2001.27.279

[24] Pavlovas, V. (2006) Energy Savings in Existing Swedish Apartment Buildings. Chamlers University of Technology, Göteborg.

[25] Jokl, M.V. (1998) Evaluation of Indoor Air Quality Using the Decibel Concept Based on Carbon Dioxide and TVOC. Building and Environment, 35, 677-697. http://dx.doi.org/10.1016/S0360-1323(99)00042-6

[26] Kalamees, T., Ilomets, S., Arumägi, E., Alev, Ü., Kõiv, T.-A., Mikola, A., Kuusk, K. and Maivel, M. (2011) Indoor Hygrothermal Conditions in Estonian Old Multi-storey Brick Apartment Buildings. The 12th International Conference on Indoor Air Quality and Climate, Austin, 5-10 June 2011, 6 p. 